УДК [004.92+004.32.8]:378

В. П. Беляев, О. С. Придачук

Белорусский государственный технологический университет

\title{
ИЗОБРАЗИТЕЛЬНАЯ ИНФОРМАЦИЯ В ЭЛЕКТРОННОМ ИЗДАНИИ
}

В статье приводятся результаты разработки электронного мультимедийного издания «Изучение электронной световой завесы». Показаны приемы обработки изображений элементов принципиальной электрической схемы для создания оригинала информационно-зрительного восприятия. В условиях разнообразных сред обучения система дистанционного образования органически требует такой учебно-методической лабораторной базы по электротехническим дисциплинам, в частности в электронном университете БГТУ. При создании указанного электронного издания была привлечена платформа компании Adobe Systems для создания веб-приложений или мультимедийных презентаций, а именно среда Adobe Flash CS6.

Поскольку электронное издание носит учебный характер, то оно имеет традиционное методическое построение, т. е. обладает теоретической частью, электронным стендом и вспомогательными разделами. Наглядное усвоение теоретического материала достигается работой на оборудовании виртуального лабораторного стенда. В статье приводятся скриншоты экрана монитора, на которых демонстрируются основные результаты обработки изображений для электронного стенда и дана мотивация применения этой обработки. Для усиления логической связи электрической схемы световой завесы и ее физического расположения на полиграфическом оборудовании создано сложное изображение стенда в режиме работы световой завесы при выполнении ее основной функции. Электронное издание прошло положительную апробацию при проведении лабораторных работ по дисциплине «Электронные устройства полиграфического оборудования».

Ключевые слова: полиграфия, электронное издание, электронные устройства, лабораторный практикум.

Для цитирования: Беляев В. П., Придачук О. С. Изобразительная информация в электронном издании // Труды БГТУ. Сер. 4, Принт- и медиатехнологии. 2021. № 2 (249). С. 26-31.

\author{
V. P. Belyaev, O. S. Pridachuk \\ Belarusian State Technological University
}

\section{IMAGING INFORMATION IN THE ELECTRONIC PUBLICATION}

The article presents the results of the development of the electronic multimedia publication "Study of the Electronic Light Curtain". Methods of image processing of elements of a basic electrical circuit for creating an original of information-visual perception are shown. In the conditions of various learning environments, the distance education system organically requires such an educational and methodological laboratory base for electrical disciplines, in particular, at the electronic university of BSTU. When creating this electronic edition, the platform of the Adobe Systems company was involved for creating web applications or multimedia presentations, namely the Adobe Flash CS6 environment.

Since the electronic edition is educational in nature, it has a traditional methodological structure, that is, it has a theoretical part, an electronic stand and auxiliary sections. Visual assimilation of theoretical material is achieved by working on the equipment of a virtual laboratory stand. The article contains screenshots of the monitor screen, which demonstrate the main results of image processing for an electronic stand and the motivation for using this processing is given. To enhance the logical connection of the electrical circuit of the light curtain and its physical location on the printing equipment, a complex image of the stand was created in the operating mode of the light curtain while performing its main function. The electronic edition has passed positive approbation during laboratory work in the discipline "Electronic devices of printing equipment".

Key words: printing, electronic publication, electronic devices, laboratory practice.

For citation: Belyaev V. P., Pridachuk O. S. Imaging information in the electronic publication. Proceedings of BSTU, issue 4, Print- and Mediatechnologies, 2021, no. 2 (249), pp. $26-31$ (In Russian).

Введение. Одним из видов продукции учебного характера является электронное издание. Как прием обучения оно органически вписывается в систему дистанционного обучения высшего учебного заведения и становится весьма актуальным в экстренных условиях взаимоотношений людей, например в возникшей в настоящее время ситуации с пандемией (коронавирусом). 
При разработке электронного издания по технической дисциплине зачастую появляется необходимость изготовления для нее лабораторного практикума с определенным интеллектуальным уровнем. Успех обучения при выполнении лабораторного практикума достигается путем использования инновационных информационных технологий, например Flash-технологий, которые создают условия анализа и адекватной реакции на действия обучающегося при соблюдении дидактических принципов в образовании, например содержательности, доступности, научности, последовательности, наглядности и т. п. $\lceil 1,2,3\rceil$. Одна из них Adobe Flash - мультимедийная платформа компании Adobe Systems для создания веб-приложений или мультимедийных презентаций. Создание лабораторного практикума на этой основе рассматриваем как мультимедийную презентацию. В основу лабораторного практикума по технической дисциплине закладываются приемы и методы моделирования явлений, процессов, устройств и т. п. В лабораторной работе средствами текстовой и изобразительной информации доводят до обучающегося суть ее содержания, поскольку изобразительная информация - всеобъемлющий и наиболее емкий источник сведений об окружающем мире $[4,5,6]$. Так, на кафедре полиграфического оборудования и систем обработки информации БГТУ при подготовке инженеров-электромехаников для электротехнической дисциплины «Электронные устройства полиграфического оборудования» разрабатываются лабораторные работы на основе Flash-технологии [7, 8].

Следует обратить внимание на то, что обработка изобразительной информации в таком электронном издании, как лабораторная работа, несколько отличается от традиционного понимания обработки изобразительной информации в полиграфии, где создается репродукционный оригинал на творческой, редакционной стадии издательско-полиграфического процесса. Однако приемы представления объектов, анимация объектов, компьютерная графика, применение цвета, мультимедиаконтейнер, физическая точность, механическое масштабирование - все может принять участие в создании электронного издания $[9,10]$.

Основная часть. В предлагаемом электронном лабораторном практикуме изготавливаемый продукт - это электронный стенд (электрические принципиальные схемы электронных устройств и алгоритмы их функционирования), а также сопровождающие его работу теоретическая часть, порядок выполнения работы, тестирование знаний по изученному материалу, например «Изучение электронной световой завесы». В электронном стенде создается изобразительная информация об электронных и коммутационных аппаратах, их элементах (обмотках, контактах и т. п.), электродвигателях и т. п. Анимация их функционирования в соответствии с алгоритмом прописана в теоретической части и порядке выполнения работы $[13,14]$.

В своем арсенале Adobe Flash имеет графические форматы, которые могут быть векторными или растровыми. Графический формат это способ записи графической информации. Графические форматы файлов предназначены для хранения изображений, таких как фотографии и рисунки. Использование растрового формата придает определенный оттенок восприятия обучающимся созданной изобразительной информации, например аббревиатура учебной дисциплины на титуле лабораторной работы (рис. 1). В информативном и эстетическом отношении изобразительная информация обращена к психовизуальному восприятию. Она формируется, отчасти используя интуитивные, эмпирические подходы и субъективные оценки. Например, визуальное сравнение цветных изображений ведется в оговоренных условиях наблюдения. В рассматриваемом здесь мультимедийном продукте это индикация цветом этапов последовательной работы электрических аппаратов, их контактов, диодов, световых зон. При обработке изображений возникает проблема так называемой совместимости различных источников изображений по входу в целях достижения визуальной однородности воспроизводимых копий, например для изображения обмотки и контактов электрического аппарата. Для художественного оформления электронного издания на авторской стадии применяется компьютерная графика. Раскроем сущность результатов разработки лабораторной работы «Изучение электронной световой завесы», титул и меню которой приведен на рис. 1 [11]. Меню позволяет при любой необходимости перейти к требуемому разделу лабораторной работы, что достигается наведением курсора мышью на надпись, например «Электронный стенд», и кликанием левой клавишей мыши. Откроется изображение принципиальной электрической схемы, демонстрирующей работу электронной световой завесы на примере одноножевой резальной машины.

Эта изобразительная информация позволяет изучить структурное построение схемы, элементный состав, а текстовая информация дает разъяснения о названиях элементной базы схемы [15]. Наведение курсора мышки на эту схему и кликание левой клавишей мыши откроет изображение начального состояния схемы лабораторного стенда (рис. 2). Начинается использование цвета для раскрытия изображением состояния элементов схемы (рис. 3). 


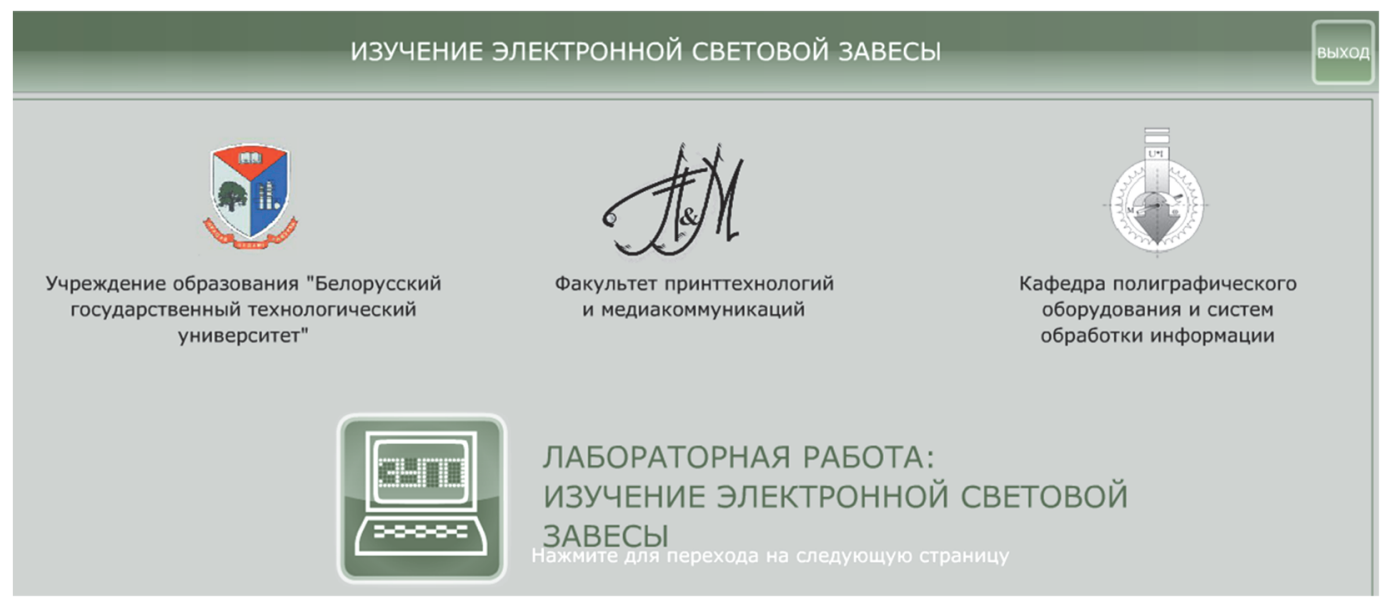

$a$

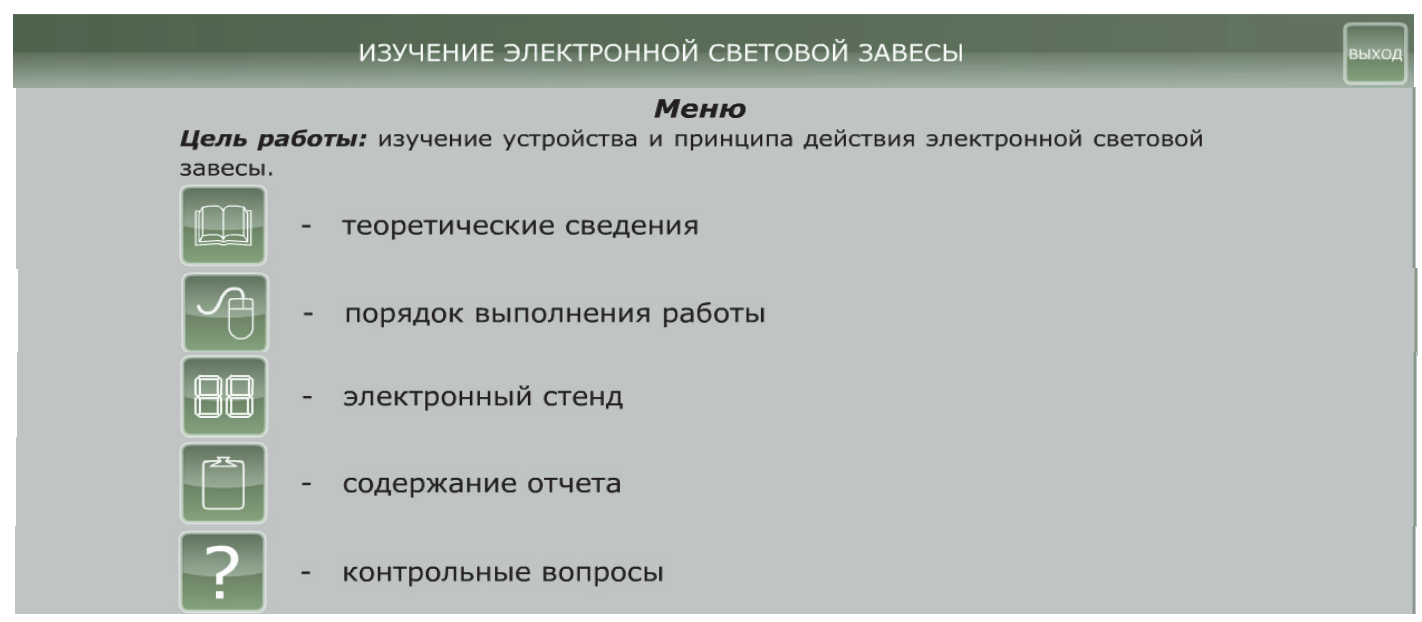

6

Рис. 1. Изображение титула ( $a$ ) и меню (б) электронного стенда

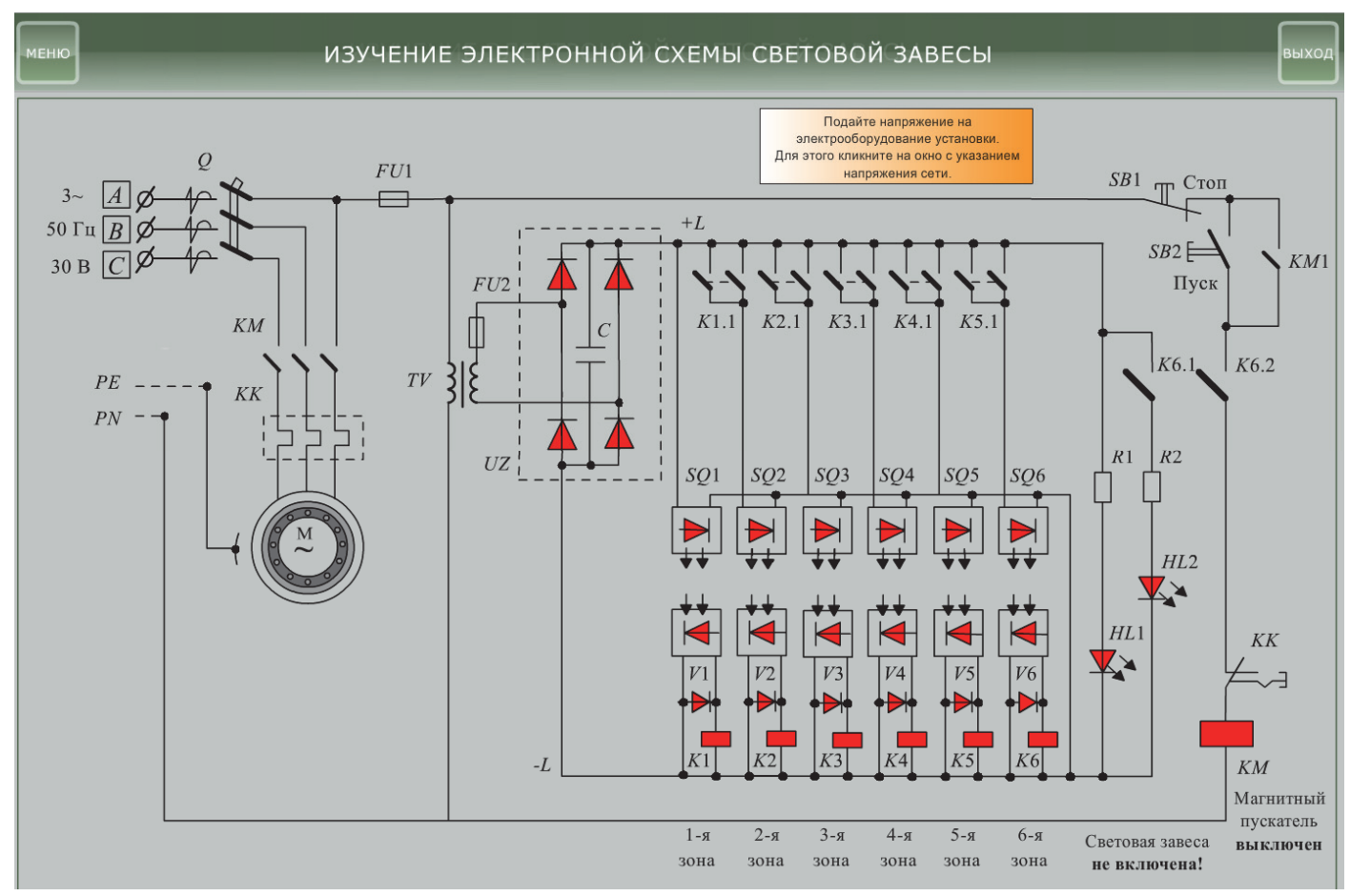

Рис. 2. Изображение исходного состояния схемы электронного стенда 


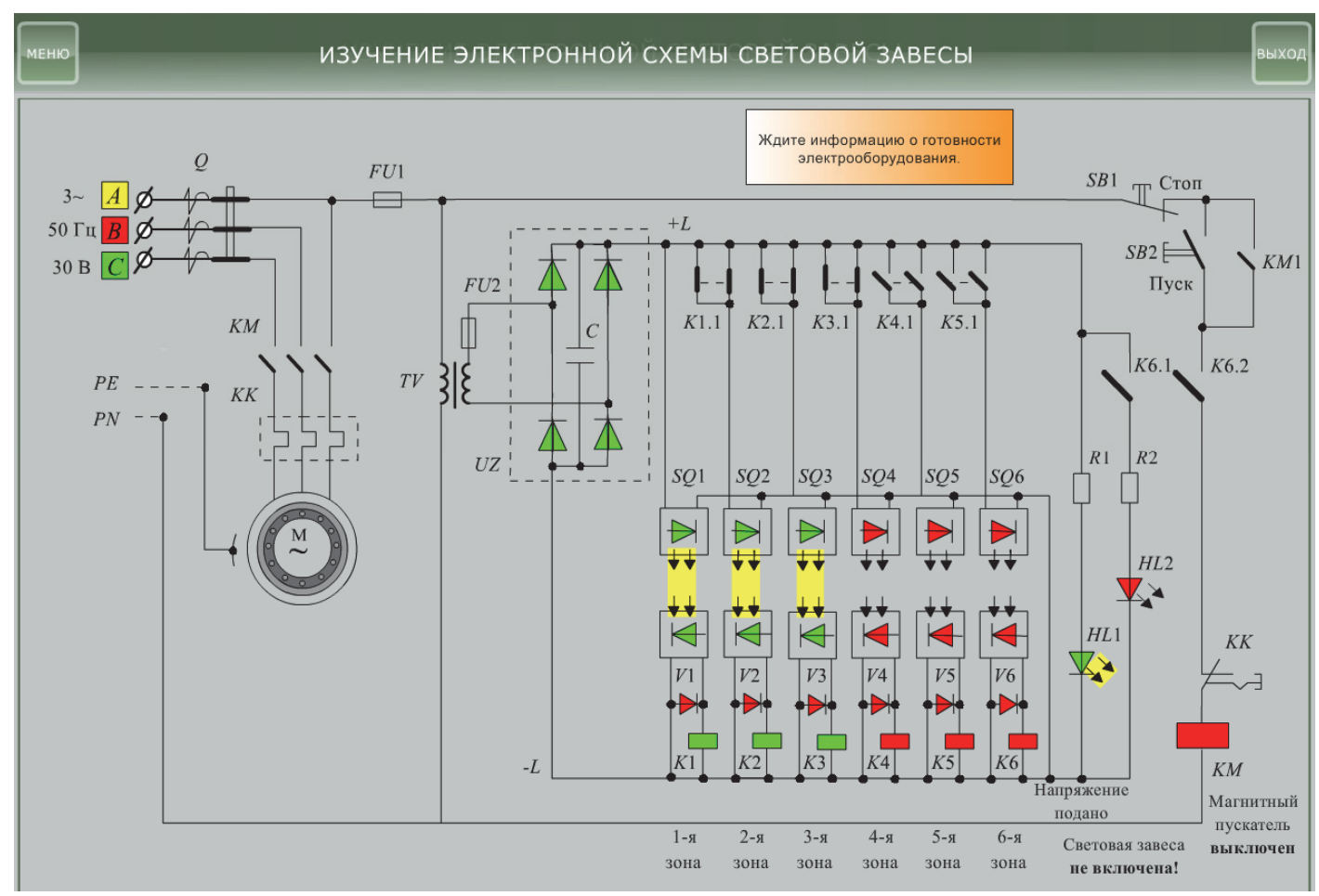

Рис. 3. Изображение схемы стенда, показывающее приведение световой завесы в рабочее состояние

В частности изображается цветовое (согласно ГОСТу) обозначение фаз трехфазной электрической сети, выключенное (нерабочее) состояние диодов $V$, катушки пускателя $K M$, световых индикаторов $H L$ - красный цвет.

Здесь же появляются информационные подсказки обучающемуся для дальнейшего управления схемой стенда. По подсказке он включает автоматический выключатель $Q$ и подает трехфазное напряжение питания на схему, что приводит к включению диодов неуправляемого выпрямителя $U Z$ и светоизлучателей (зеленый цвет) и фотоприемников (зеленый цвет) охранных световых зон завесы $S Q 1 \ldots S Q 6$ (желтый цвет).

Для визуального восприятия приведения электронной завесы в рабочее состояние действие схемы разворачивается с определенным интервалом времени. При этом индикацией цветом показывается последовательность работы ее составных элементов - диодов, светодиодов, реле. После прихода завесы в рабочее состояние включается световая индикация «Световая завеса включена» (светодиод HL2). Опробование защитной функции завесы выполняется на работе электродвигателя $M$, приводящего в движение, например, механизм прижима одноножевой резальной машины. Его включение обучающийся осуществляет наведением курсора мышью на изображение кнопки $S B 2$ и кликанием левой клавишей мыши. Контакт кнопки замыкается, и напряжение питания переменного тока от сети подается на катушку пускателя $K M$. Пускатель включается и своими замыкающими силовыми контактами присоединяет трехфазную обмотку статора асинхронного двигателя к напряжению сети. Ротор двигателя начинает вращаться (показывается анимационным его вращением). После нескольких секунд его работы появляется посторонний объект в виде руки и окно с директивой «Нажмите на руку». Обучающийся реализует эту подсказку, и схема предлагает опробовать работу световой завесы, выполнив появившуюся директиву «Кликните курсором любую охранную зону». Выполнение ее приводит к появлению руки в выбранной обучающимся зоне и началу реализации световой завесы защитной функции.

Усиление логической связи электрической схемы световой завесы с ее физическим расположением на полиграфическом оборудовании, в частности на рабочем столе одноножевой резальной машины, при ее функционировании в электрической схеме создается появлением изображения световой завесы в виде световых зон на изображении машины (рис. 4). На рисунке синхронно с последовательным выключением аппаратов $S Q$, $V, K$ исчезают изображения световых потоков охранных зон, подтверждая работу световой завесы. После ее срабатывания показывается работа аппаратов схемы по выключению электродвигателя как элемента, приводящего в движение одноножевую резальную машину, чем подтверждается защитная функция световой завесы. 


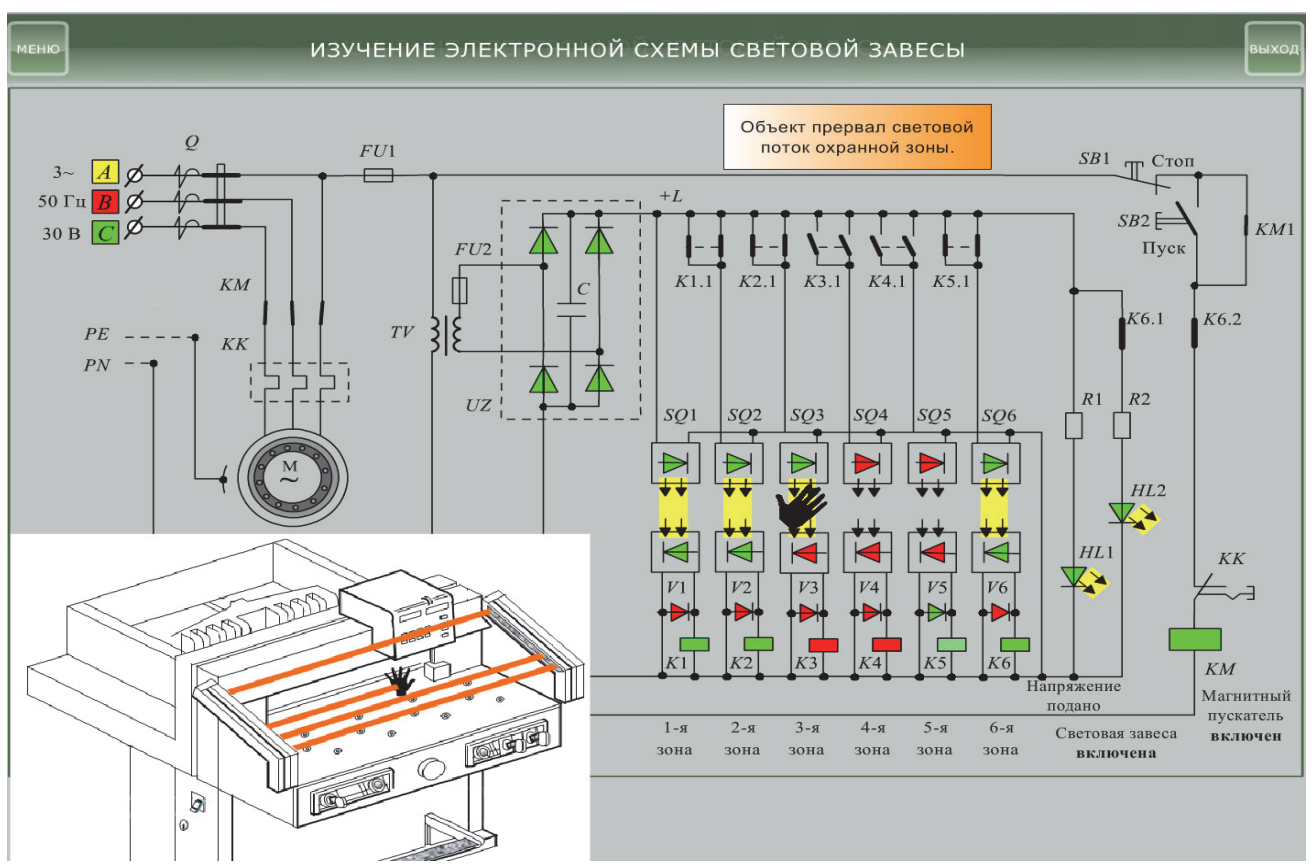

Рис. 4. Изображение схемы стенда, демонстрирующей работу световой завесы в режиме перекрытия объектом одной из охранных зон

Обучающийся по подсказке может проверить работу световой завесы для любой другой защитной зоны. Другим приемом изобразительности выполнены контакты аппаратов, например, замыкающих. Они выполнены большей толщины, чтобы их изображение при замкнутом состоянии не сливалось с изображением электрических линий. Для демонстрации включенного состояния электродвигателя создано анимационное движение его короткозамкнутого ротора, причем в виде определенной интерпретации обмотки ротора - «беличьей клетки».

Заключение. Оценивая создание электронного издания в виде лабораторной работы, сформулируем некоторые выводы:

- лабораторная работа создана как изобразительный оригинал для информационного и зри- тельного восприятия, а не для репродукционного процесса;

- мультимедийный продукт позволяет при изложении материала дисциплины визуализировать определенные стороны технических процессов, которые обучающийся не имеет возможности увидеть на физическом объекте (например, перекрытие световых потоков, последовательность срабатывания аппаратов, включенное//выключенное состояние диодов и т. п.);

- электронное издание обладает определенным интеллектуальным уровнем, поскольку предоставляет компьютерную среду, которая анализирует и адекватно реагирует на действия обучающегося;

- визуализация изучаемого объекта закрепляет материал в памяти обучающегося.

\section{Список литературы}

1. Вуль В. А. Электронные издания: учебник. М.: МГУП, 2013. 803 с.

2. Кузнецов Ю. В. Технология обработки изобразительной информации. СПб.: Петербургский институт печати, 2002. $312 \mathrm{c}$.

3. Технология информационного моделирования - будущие перспективы и пути эволюции. URL: https://www.elec.ru/publications/menedzhment/5552/ (дата обращения: 13.02.2021).

4. Дронов В. А. Macromedia Flash MX. СПб.: БХВ-Петербург, 2003. 848 с.

5. Лапин П. Самоучитель Flach MX. СПб.: Издательский Дом ПИТЕР, 2003. 153 с.

6. Технология Macromedia Flash. URL: https://topref.ru/referat/50722.html (дата обращения: 10.03.2021).

7. Беляев В. П. Электронные устройства автоматики. Минск: БГТУ, 2008. 136 с.

8. Черных И. В. Моделирование электротехнических устройств в MATLAB, SimPowerSystem и Simulink. М.: ДМК Пресс; СПб.: Питер, 2008. 288 с.

9. Создание анимации в программе macromedia flash. URL: http://csaa.ru/sozdanie-animacii-vprogramme-macromedia-flash/ (дата обращения: 10.03.2021).

10. Моделирование физических процессов средствами Macromedia Flash технологий. URL: http://5fan.ru/wievjob.php?id=5716 (дата обращения: 10.03.2021).

11. Беляев В. П. Электрооборудование полиграфических машин. Минск: БГТУ, 2014. 367 с. 
12. Ивановский Р. И. Компьютерные технологии в науке и образовании. Минск: Выш. шк., 2006. 430 с.

13. Алиев И. И., Гурина И. А. Моделирование электротехнических устройств. Черкесск: БИЦ СевКавГГТА, 2013. 103 с.

14. Штеннинков Д. Г. Macromedia Flash. Основы программирования. URL: https://cyberleninka.ru/ article/n/macromedia-flash-osnovy-programmirovaniya-prosteyshie-skripty-urok-3 (дата обращения: 15.03.2021).

15. Сандерс Б. Flash ActionScript. СПб.: Питер. 2001. 196 c.

\section{References}

1. Vul', V. A. Elektronnyye izdaniya [Electronic editions]. Moscow, MGUP Publ., 2013. 803 p.

2. Kuznetsov Yu. V. Tekhnologiya obrabotki izobrazitel'noy informatsii [Processing technology of graphic information]. St. Petersburg, Peterburgskiy institut pechati Publ., 2002. 312 p.

3. Tekhnologia informatsionnogo modelirovaniya - budushchiye perspectivy i puti evolutsii [Information Modeling Technology - Future Perspectives and Paths of Evolutiontion]. Available at: https://www.elec.ru/ publications/menedzhment/5552/ (accessed 13.02.2021).

4. Dronov V. A. Macromedia Flash MX [Macromedia Flash MX]. St. Petersburg, BkHV-Peterburg Publ., 2003. 848 p.

5. Lapin P. Samouchitel' Flach MX [Self-instruction Flach MX]. St. Petersburg, Izdatel'skiy Dom PITER Publ., 2003. 153 p.

6. Tekhnologiya Makromedia Flash [Macromedia Flash technology]. Available at: https:/topref.ru/ referat $/ 50722 . h t m l$ (accessed 10.03.2021).

7. Belyayev V. P. Elektronnyye ustroystva avtomatiki [Electronic devices of automation]. Minsk, BGTU Publ., 2008. 136 p.

8. Chernykh I. V. Modelirovaniye elektrotekhnicheskikh ustroystv v MATLAB, SimPowerSystem $i$ Simulink [Simulation of electrical devices in MATLAB, SimPowerSystem and Simulink]. Moscow, DMK Press Publ.; St. Petersburg, Piter Publ., 2008. 288 p.

9. Sozdaniye animatsii v programme MacromediaFlash [Animation creation in macromedia flash program]. Available at: http://csaa.ru/sozdanie-animacii-v-programme-macromedia-flash/ (accessed 10.03.2021).

10. Modelirovaniye fizicheskikh protsessov sredstvami Macromedia Flash tekhnologiy [Modeling physical processes by means of Macromedia Flash technologies]. Available at: http://5fan.ru/wievjob.php?id=5716 (accessed 10.03.2021).

11. Belyaev V. P. Elektrooborudovaniye poligraficheskikh mashin [Electrical equipment for printing machines]. Minsk, BGTU Publ., 2014. 367 p.

12. Ivanovskiy R. I. Komp'yuternyye tekhnologii v nauke $i$ obrazovanii [Computer technologies in science and education]. Minsk, Vysh. shk. Publ., 2014. 367 p.

13. Aliev I. I., Gurina I. A. Modelirovaniye elektrotekhnicheskikh ustroystv [Simulation of electrical devices]. Cherkessk, BITs SevKavGGTA Publ., 2013. 103 p.

14. Shtennikov D. G. Macromedia Flash. Osnovy programmirovaniya [Macromedia Flash. Basics of programming]. Available at: https://cyberleninka.ru/article/n/macromedia-flash-osnovy-programmirovaniyaprosteyshie-skripty-urok-3 (accessed 15.03.2021).

15. Sanders B. Flash ActionScript [Flash ActionScript]. St. Petersburg, Piter Publ., 2001. 196 p.

\section{Информация об авторах}

Беляев Валерий Павлович - кандидат технических наук, доцент, доцент кафедры полиграфического оборудования и систем обработки информации. Белорусский государственный технологический университет (220006, г. Минск, ул. Свердлова, 13a, Республика Беларусь). E-mail: beliaev@belstu.by

Придачук Ольга Сергеевна - студентка кафедры полиграфического оборудования и систем обработки информации. Белорусский государственный технологический университет $(220006$, г. Минск, ул. Свердлова, 13a, Республика Беларусь). E-mail: olya_olya_pridachuk@mail.ru

\section{Information about the authors}

Belyayev Valeri Pavlovich - PhD (Engineering), Associate Professor, Assistant Professor, the Department of Editing Equipment and Information Processing Systems. Belarusian State Technological University (13a, Sverdlova str., 220006, Minsk, Republic of Belarus). E-mail: beliaev@belstu.by

Pridachuk Ol'ga Sergeyevna - student, the Department of Editing Equipment and Information Processing Systems. Belarusian State Technological University (13a, Sverdlova str., 220006, Minsk, Republic of Belarus). E-mail: olya olya_pridachuk@mail.ru 